\title{
Increased endothelin-1 production in diabetic patients after cardioplegic arrest and reperfusion impairs coronary vascular reactivity: Reversal by means of endothelin antagonism
}

\author{
Subodh Verma, MD, $\mathrm{PhD}^{\mathrm{a}}$ \\ Andrew Maitland, MD ${ }^{\mathrm{b}}$ \\ Richard D. Weisel, MD ${ }^{\mathrm{a}}$ \\ Paul W. M. Fedak, MDa \\ Shu-Hong Li, MSc ${ }^{a}$ \\ Donald A. G. Mickle, MD \\ Ren-Ke Li, MD, PhD ${ }^{\mathrm{a}}$ \\ Lawrence $\mathrm{Ko}, \mathrm{BSc}^{\mathrm{a}}$ \\ Vivek Rao, MD, $\mathrm{PhD}^{\mathrm{a}}$
}

See related editorial on page 1031.

\begin{abstract}
From the Division of Cardiac Surgery, Toronto General Hospital, University of Toronto, Toronto, Ontario, Canada, ${ }^{\mathrm{a}}$ and the Division of Cardiac Surgery, Foothills Hospital, University of Calgary, Calgary, Alberta, Canada. ${ }^{\mathrm{b}}$
\end{abstract}

Supported by the Heart and Stroke Foundation of Ontario (R.D.W.), Canadian Diabetes Association (R.D.W., V.R., S.V.), and Physicians Services Incorporated (S.V., R.D.W.). S.V. and P.W.M.F. are fellows of the Canadian Institutes of Health Research and Heart and Stroke Foundation of Canada. S.V. was the C. Walton Lillehei Forum Finalist.

Read at the Eighty-first Annual Meeting of The American Association for Thoracic Surgery, San Diego, Calif, May 6-9, 2001.

Received for publication May 15, 2001; revisions requested July 9, 2001; revisions received Nov 12, 2001; accepted for publication Nov 13, 2001.

Address for reprints: Richard D. Weisel, MD, FRCSC, Professor and Chairman, Division of Cardiac Surgery, The Toronto General Hospital, EN 14-215, 200 Elizabeth St, Toronto, Ontario, M5G 2C4 Canada (E-mail: richard.weisel@uhn.on.ca).

J Thorac Cardiovasc Surg 2002;123:1114-9

Copyright (C) 2002 by The American Association for Thoracic Surgery

0022-5223/2002 \$35.00+0 $\quad \mathbf{1 2 / 6 / 1 2 1 9 7 2}$

doi:10.1067/mtc.2002.121972
Objectives: Evidence has accrued to suggest that diabetic patients face an increased risk of ischemic events and low output syndrome and might mount an inordinate response to ischemia and reperfusion. Because hyperglycemia is a potent stimulus for endothelin-1 production, we hypothesized that increased production, action, or both of endothelin-1 in diabetes might represent an important mediator of endothelial dysfunction in patients with that disease. To this aim, we compared the effects of cardioplegic arrest and reperfusion on coronary sinus effluent endothelin-1 levels and atrial arteriolar vascular responses in diabetic and case-matched nondiabetic patients undergoing coronary artery bypass grafting.

Methods: In study 1 coronary sinus effluent endothelin-1 levels were assessed at baseline and at 1 and 10 minutes after reperfusion in 13 diabetic and 12 nondiabetic patients matched for age, ejection fraction, Parsonnet score, and crossclamp time. In study 2 vascular responses of atrial arterioles subjected to perioperative ischemiareperfusion were evaluated with videomicroscopy. Atrial microvessels (from appendages) were obtained before and after removal of the aortic crossclamp, and vascular responses to exogenously administered endothelin-1 $\left(10^{-10} \mathrm{~mol} / \mathrm{L}\right)$ and substance $\mathrm{P}\left(10^{-8} \mathrm{~mol} / \mathrm{L}\right)$ were studied in the presence or absence of BQ-123, an endothelin A receptor antagonist.

Results: Diabetic patients elaborated more endothelin-1 at 1 and 10 minutes after reperfusion $(P=.01)$. Endothelin-1-mediated vasoconstriction was similar in diabetic and nondiabetic atrial microvessels before cardioplegic arrest and cardiopulmonary bypass. After cardiopulmonary bypass and reperfusion, endothelin-1mediated vasoconstriction was enhanced in both groups; however, this response was greater in microvessels from diabetic patients $(P=.02)$. BQ-123, the endothelin A antagonist, attenuated the effects of bypass and reperfusion on endothelin-1-mediated vasoconstriction in both groups $(P=.01)$. Substance $\mathrm{P}$-mediated vasodilatation was similar in diabetic and nondiabetic atrial microvessels before bypass. After bypass and reperfusion, substance P-mediated vasodilatation was diminished in both groups; however, this response was more pronounced in the diabetic group $(P=.003)$. BQ-123 coincubation restored substance P-mediated vasodilatation in both groups.

Conclusions: We determined the following: (1) the coronary effluent release of endothelin-1 is higher in diabetic than in nondiabetic patients after cardiopulmonary bypass and reperfusion; (2) diabetic coronary microvessels respond to bypass and reperfusion with greater endothelin-1-mediated vasoconstriction and diminished nitric oxide-mediated vasodilatation; and (3) these effects are attenuated by endothelin antag- 
onism. Endothelin-1 might be an important mediator of ischemia-reperfusion injury in patients with diabetes. Furthermore, use of endothelin receptor antagonists might be a novel strategy for improving the resistance of the diabetic heart to cardioplegic arrest and reperfusion.

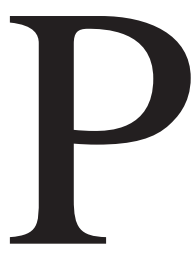

atients with diabetes are at increased risk of ischemic events. ${ }^{1-8}$ Furthermore, diabetes represents an important risk factor for poor outcomes after coronary revascularization ${ }^{9-13}$ and an independent predictor of graft occlusion. The diabetic heart elicits an exaggerated response to ischemia-reperfusion, with altered neutrophil adhesion, endothelial dysfunction, myocyte contractility, oxidative stress, and myocardial energetics. ${ }^{14-17}$ Diabetes is an independent predictor of low output syndrome after coronary artery bypass graft (CABG) surgery. ${ }^{18}$ Despite the accumulating evidence that myocardial ischemic injury is increased in diabetes, few, if any, diabetes-specific interventions have been investigated to protect the heart from ischemic injury during $\mathrm{CABG}$ surgery.

Endothelin-1 (ET-1) is one of the most potent vasoconstrictors known and has been implicated in the development of a number of cardiovascular diseases, including congestive heart failure, pulmonary hypertension, endothelial dysfunction, atherosclerosis, and vasospasm. Because hyperglycemia is a potent stimulus of ET-1 production, we hypothesized that increased production, action, or both of ET-1 might represent an important mediator of endothelial dysfunction in diabetes. To this aim, we compared the effects of cardioplegic arrest and reperfusion on coronary sinus effluent ET-1 levels and atrial arteriolar vascular responses in diabetic and case-matched nondiabetic patients undergoing $\mathrm{CABG}$.

\section{Patients and Methods}

\section{Study 1: Coronary Sinus Effluent Production of ET-1}

Thirteen patients with type 2 diabetes and 12 nondiabetic patients undergoing elective CABG surgery were studied. The nondiabetic patients were case matched for age, ejection fraction, number of vessels bypassed, Parsonnet score, and crossclamp time (Table 1). Cardioplegic arrest was achieved by means of cold antegrade infusion and maintained with intermittent retrograde infusions. Additional infusions were given after each distal anastomosis was completed. The preoperative and perioperative management of patients was similar between groups. A coronary sinus blood sample was obtained from the retrograde cardioplegia catheter before the initiation of cardiopulmonary bypass and 1 and 10 minutes after removal of the aortic crossclamp. For determination of ET-1 levels, plasma samples were acidified with $0.25 \mathrm{~mol} / \mathrm{L}$ $\mathrm{HCl}$ and then passed through SEP columns. After extraction, the eluate was analyzed for ET-1 by using a commercial ELISA (R\&D systems). Data are expressed as picograms per milliliter.

\section{Study 2: Vascular Responses of Atrial Microvessels}

A segment of right atrial appendage was harvested after systemic heparinization and before CPB (control) and 15 minutes after removal of the aortic crossclamp and before administration of protamine (reperfusion group). Atrial microvessels (range, 150$250 \mu \mathrm{m}$ ) were dissected out (at $4^{\circ} \mathrm{C}$ ) and transferred to an experimental chamber of an arteriograph filled with oxygenated physiologic salt solution (Krebs buffer) and maintained at $37^{\circ} \mathrm{C}(\mathrm{pH}$ 7.4). Each vessel was secured onto a proximal glass microcannula with a tip diameter of 40 to $80 \mu \mathrm{m}$ and secured with 10-0 sutures. After several minutes of perfusion, the distal outflow cannula was closed, and the transmural pressure was slowly increased to $40 \mathrm{~mm}$ $\mathrm{Hg}$ by using an electronic pressure Servo System (Living Systems). The arteriograph with the cannulated pressurized artery was mounted on the stage of an inverted microscope with a monochrome video camera attached to a viewing tube and was allowed to equilibrate for 60 minutes. Arterial dimensions were measured with the video system. Myogenic tone developed spontaneously (10\%-15\%) and consistently during equilibration procedures, decreasing the luminal diameter. Change in internal diameter was recorded in response to each intervention. The baseline internal diameter was determined immediately after cannulation and transfer to the chamber before pressurization or the development of spontaneous tone (maximal passive diameter). After the vessels had been allowed to equilibrate (for 30-60 minutes), they were stimulated with ET-1 $\left(10^{-10} \mathrm{~mol} / \mathrm{L}\right)$ in the presence and absence of BQ-123 $\left(\right.$ ET $_{\mathrm{A}}$ antagonist, $1 \mu \mathrm{mol} / \mathrm{L}$, used 15 minutes before ET1). The percentage of reduction in internal diameter (from baseline) was recorded as the index of ET-1-mediated vasoconstriction. To examine nitric oxide (NO)-mediated vasorelaxation, we studied the effects of substance $\mathrm{P}\left(10^{-8} \mathrm{~mol} / \mathrm{L}\right)$ on the percentage of increase in internal diameter in arteries with internal diameters of $40 \%$ to $50 \%$ of the baseline value (achieved either spontaneously

\section{TABLE 1. Patient demographics}

\begin{tabular}{|c|c|c|c|}
\hline & $\begin{array}{l}\text { Diabetic patients } \\
\qquad(\mathrm{n}=13)\end{array}$ & $\begin{array}{c}\text { Nondiabetic } \\
\text { patients } \\
(\mathrm{n}=12)\end{array}$ & $P$ value \\
\hline Age (y) & $59.6 \pm 7.3$ & $58.1 \pm 6.2$ & .42 \\
\hline LVEF, (\%) & $39.7 \pm 4.8$ & $46.4 \pm 5.2$ & .28 \\
\hline No. of vessels bypassed & $3.2 \pm 0.8$ & $3.7 \pm 0.3$ & .52 \\
\hline Parsonnet score & $9.3 \pm 2.2$ & $8.7 \pm 2.3$ & .37 \\
\hline Crossclamp time (min) & $84.5 \pm 7.3$ & $78.3 \pm 13.2$ & .31 \\
\hline Random glucose (mmol/L) & $10.2 \pm 2.1$ & $5.9 \pm 1.8^{*}$ & .03 \\
\hline Total cholesterol (mmol/L) & $5.7 \pm 0.4$ & $4.1 \pm 0.4^{*}$ & .02 \\
\hline LDL cholesterol (mmol/L) & $3.6 \pm 0.3$ & $2.2 \pm 0.5^{*}$ & .02 \\
\hline
\end{tabular}

$L V E F$, Left ventricular ejection fraction; $L D L$, low-density cholesterol.

*Different from diabetic group. 


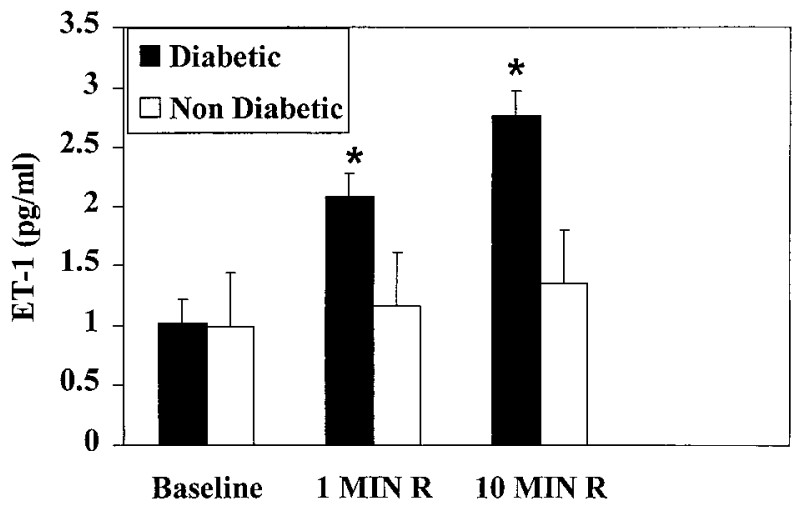

Figure 1. Plasma ET levels at baseline and after 1 and 10 minutes of reperfusion (removal of the aortic crossclamp) in diabetic and case-matched nondiabetic patients. ET-1 levels are similar at baseline; however, after reperfusion, the coronary sinus effluent ET-1 release was higher in the diabetic than in the nondiabetic group. ${ }^{*} \boldsymbol{P}=.01$ versus the nondiabetic group. MIN $\boldsymbol{R}$, Minutes of reperfusion.

or with the addition of U46619, a thromboxane analogue). In some segments we studied the effects of BQ-123 (1 $\mu \mathrm{mol} / \mathrm{L})$ on substance P-induced vasorelaxation. Because ET-1 causes potent and protracted vasoconstriction, only one concentration of ET-1 was studied. The responses are reported as the percentage of increase or decrease in internal diameter (with $100 \%$ representing the maximal baseline diameter before the vessels were pressurized).

\section{Statistical Analysis}

Data are presented as means \pm SEM. Data were compared with 2-way analysis of variance. When the F ratio indicated a significant effect, differences were specified by using a Newman-Keuls test for post hoc comparisons.

\section{Results}

\section{Patient Demographics}

The demographics of the patient population are presented in Table 1. The groups were similar in terms of age, ejection fraction, crossclamp time, Parsonnet score, and number of vessels bypassed. The diabetic group exhibited a higher random plasma glucose level and hemoglobin $\mathrm{A}_{1 \mathrm{C}}$ when compared with the nondiabetic group. In addition, the diabetic group had higher total cholesterol and low-density cholesterol and higher preoperative systolic blood pressure when compared with the control group. All diabetic patients were receiving oral antihyperglycemic agents, and none were taking insulin.

\section{Coronary Effluent ET-1}

The coronary sinus effluent ET-1 levels at baseline and after 1 and 10 minutes of reperfusion are depicted in Figure 1. Despite similar ET-1 release at baseline, the diabetic pa- tients elaborated significantly more ET-1 during the immediate reperfusion phase.

\section{Atrial Microvessel Function}

The baseline internal diameter of the atrial microvessels studied averaged $146 \pm 9 \mu \mathrm{m}$ in the diabetic group and $177 \pm 14 \mu \mathrm{m}$ in the nondiabetic group $(P=.17)$. At a pressure of $40 \mathrm{~mm} \mathrm{Hg}$, both groups had myogenic tone, as evidenced by a reduction in the internal diameter, and the degree of spontaneous constriction was similar between groups both before and after reperfusion (diabetic group: $15.3 \% \pm 4 \%$ vs nondiabetic group: $12.6 \% \pm 3 \%, P=.42$ ) Figure 2 depicts the effects of ET-1 $\left(10^{-10} \mathrm{~mol} / \mathrm{L}\right)$ on the percentage of decrease in internal diameter in the control and diabetic groups after cardioplegic arrest. ET-1 evoked greater vasoconstriction in both groups after reperfusion; however, this response was greater in microvessels from diabetic patients. The $\mathrm{ET}_{\mathrm{A}}$ antagonist $\mathrm{BQ}-123$ attenuated the exaggerated ET-1-mediated response in both control and diabetic microvessels (Figure 2).

The vasodilatory responses to substance $\mathrm{P}$, an NOmediated vasorelaxant, were examined in arterioles precontracted to a similar internal diameter, which was achieved with extraluminal U46619 when necessary. The internal diameter of the precontracted arteries was similar between groups (diabetic group: $42 \% \pm 7 \%$ vs nondiabetic group: $57 \% \pm 8 \%, P=.36$ ). Figure 3 depicts the endotheliumdependent responses to substance $\mathrm{P}\left(10^{-8} \mathrm{~mol} / \mathrm{L}\right)$. After reperfusion, substance P-mediated responses were attenuated in both control and diabetic arterioles. Importantly, diabetic microvessels exhibited significantly greater attenuation in substance P-mediated vasodilatation. Preincubation with BQ-123 restored substance P-mediated vasorelaxation to prereperfusion values in both groups studied (Figure 3).

\section{Discussion}

\section{Key Observations}

The following observations have been made in this study: (1) the coronary sinus effluent production of ET-1 is higher in diabetic than in nondiabetic patients after cardioplegic arrest, $\mathrm{CPB}$, and reperfusion; (2) diabetic coronary microvessels respond to $\mathrm{CPB}$ and reperfusion with greater ET-1-mediated vasoconstriction and diminished NO-mediated vasodilatation; and (3) these effects were eliminated by ET antagonism. These data suggest that ET-1 might be an important mediator of ischemia-reperfusion injury in diabetes. Furthermore, they suggest that antagonism of ET receptors might represent a potential strategy for improving the resistance of the diabetic heart to ischemic injury during cardioplegic arrest and reperfusion.

\section{Coronary Sinus Effluent ET-1 Levels}

Our data on ET-1 production support recent observations by Fogelson and associates ${ }^{19}$ demonstrating higher ET-1 pro- 


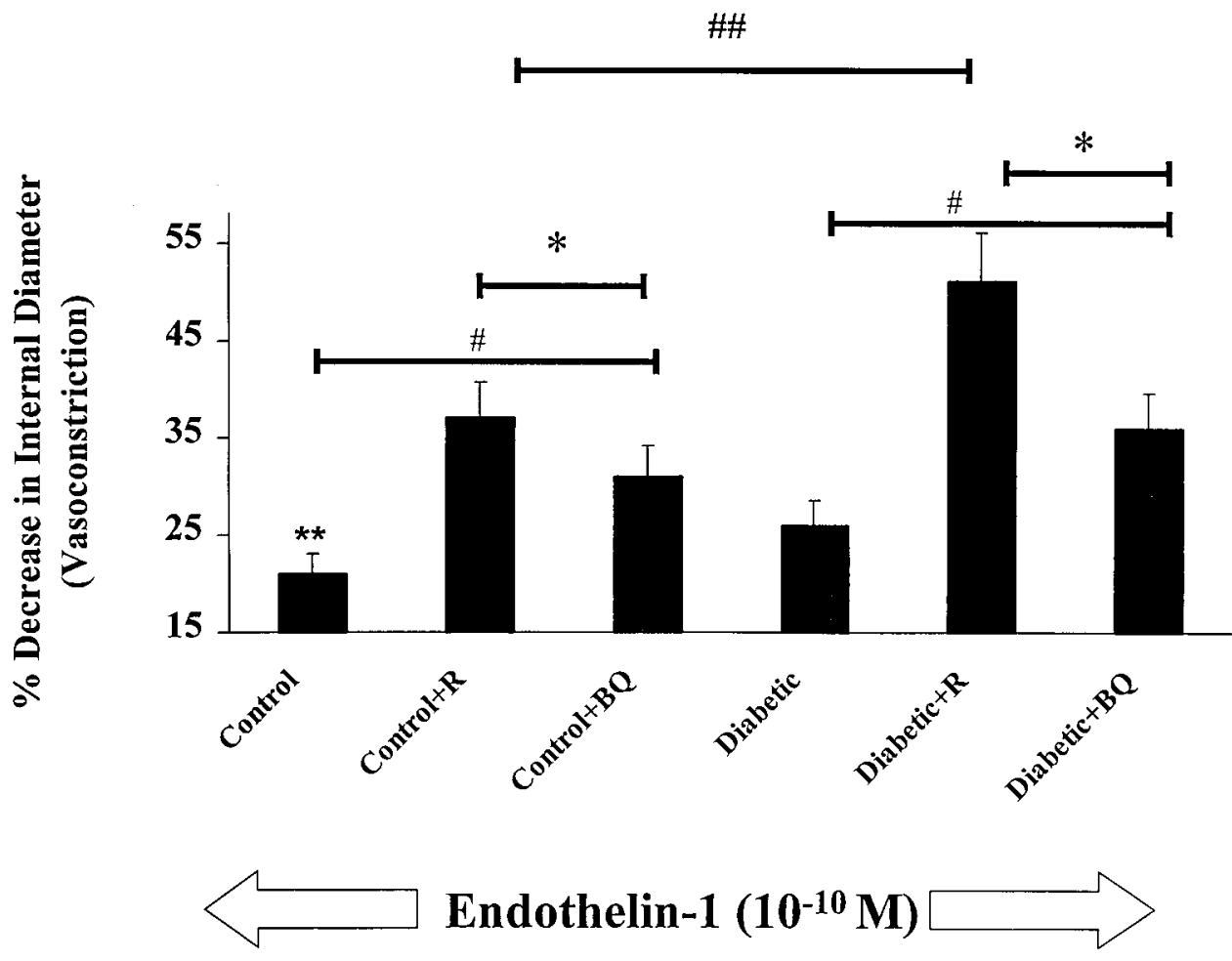

Figure 2. Percentage decrease in internal diameter (vasoconstriction) in response to $10^{-10} \mathrm{~mol} / \mathrm{L} \mathrm{ET}-1$ and the $\mathrm{ET}_{\mathrm{A}}$ antagonist B0-123. Atrial microvessels were studied in a pressurized fashion by using videomicroscopy before cardioplegia, and the results 15 minutes after removal of the aortic crossclamp were depicted. ET-1-mediated vasoconstriction was higher in both diabetic $(n=10)$ and nondiabetic $(n=11)$ microvessels; however, the vasoconstrictor effects of ET-1 were greater in diabetic arterioles. B0-123 attenuated the increased constrictor responses to ET-1 in both control and diabetic groups. ${ }^{* *} P=.01$ versus control group; \#\# $=.02$ versus control-reperfusion group; $\# P=.02$ versus control and diabetic groups; ${ }^{*} P=.03$ versus control-reperfusion and diabetic-reperfusion groups. $R$, Reperfusion.

duction in the immediate reperfusion period in diabetic patients undergoing CABG. A few issues about ET-1 levels in this study require discussion. First, we did not assess arterial ET-1 levels, and hence an index of coronary production (ie, arterial minus coronary effluent production) could not be provided. Second, we did not assess coronary sinus flow; it is possible that diabetic patients had lower coronary sinus flow after crossclamp removal, which could explain the higher ET levels. Third, no assessments of ET-1 production were made after discontinuation of CPB, and hence we are unable to assess the effects of ET-1 during this period. Fourth, we did not measure NO production. Because ET-1 and NO appear to work in concert to maintain vascular tone and reactivity, such an assessment would have provided a better index of vascular tone. However, recent studies have demonstrated similar NO release. ${ }^{20}$

Hyperglycemia is a potent stimulator of ET-1 synthesis from the endothelium..$^{21-24}$ Hyperglycemic diabetic patients might have produced more ET-1 through this mechanism. The cardiomyocyte might also be a source of ET-1, and our in vitro data presented in the accompanying article suggest that hyperglycemia might serve to increase heart cell ET-1 production. Whatever the cellular mechanism, increased ET-1 production might serve as an important mediator of generalized endothelial dysfunction, both directly by means of vasoconstriction and indirectly by means of inhibiting NO action. In addition to endothelial damage, elegant studies from Dorman and associates ${ }^{25}$ have demonstrated that ET-1 might directly impair cardiomyocyte contractility by inducing intracellular calcium overload. Hence the observation that ET-1 levels might be increased in diabetic patients is an important finding because it demonstrates that, despite similar intraoperative management, the diabetic patient responds differently to perioperative ischemia-reperfusion. Finally, it is important to appreciate that the majority of ET-1 production from the endothelium is released abluminally (toward the vascular smooth muscle and cardiomyocyte). Circulating levels represent a spillover of ET-1 and underestimate true tissue levels. Hence modest differences in coronary effluent ET-1 production might reflect much 


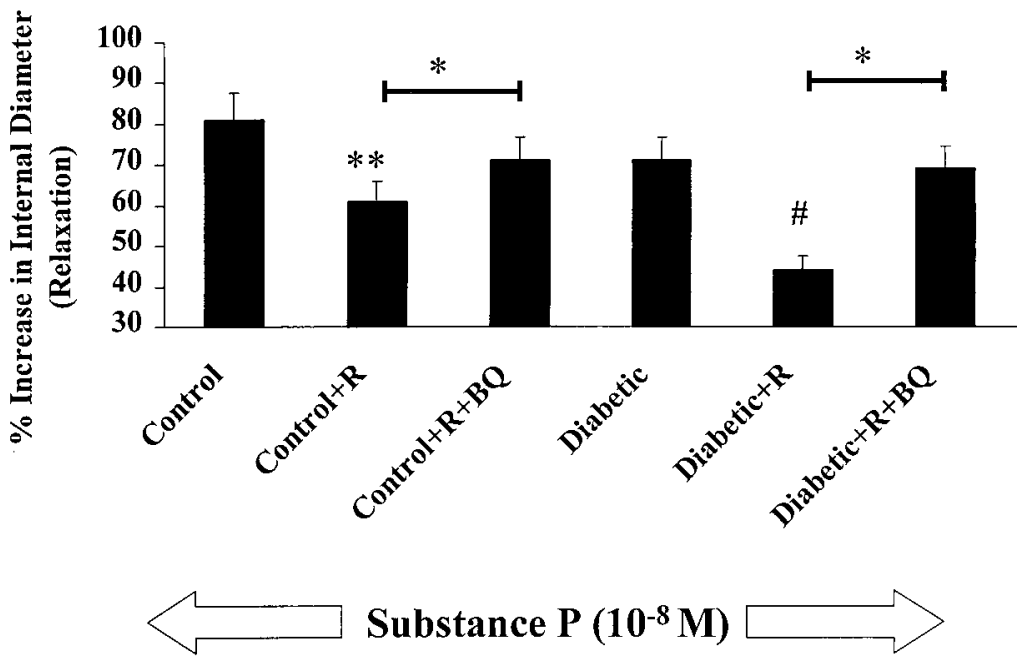

\begin{abstract}
Figure 3. Percentage increase in internal diameter (vasodilatation) in response to $10^{-8} \mathrm{~mol} / \mathrm{L}$ substance $P$ and the $\mathrm{ET}_{\mathrm{A}}$ antagonist BQ-123 in arterioles precontracted to $40 \%$ to $50 \%$ of baseline internal diameter achieved either spontaneously or with additions of U46619. Substance P-mediated vasodilatation was similar at baseline between the control and diabetic groups. The results after reperfusion are depicted. Substance P-mediated responses were attenuated in both the control and diabetic groups, but the relaxation was greater in the diabetic vessels. B0-123 prevented the decrease in substance $P$ responses in both control and nondiabetic groups. ${ }^{*} \boldsymbol{P}=.02$ versus control, diabetic, and diabetic-reperfusion groups; $\# \boldsymbol{P}=.01$ versus control, diabetic, and control-reperfusion groups; ${ }^{*} \boldsymbol{P}=$ .01 , versus control-reperfusion and diabetic-reperfusion groups.
\end{abstract}

greater tissue ET-1 concentrations in patients with diabetes. However, differences in tissue levels remain to be determined.

\section{Microvessel Function}

We found that vascular reactivity increased in both control and diabetic patients; however, the changes were greater in the diabetic patients. First, after CPB and reperfusion, vasoconstriction to similar concentrations of ET-1 was greater in diabetic microvessels compared with that seen in the nondiabetic control group. To our knowledge, this study is the first to demonstrate increased ET-1-mediated vasoconstriction in both control and diabetic patients after crossclamp release. Second, NO-mediated vasorelaxation was impaired in both groups, and the impairment in vasorelaxation was greater in the diabetic microvasculature. Extensive studies by Metais and colleagues ${ }^{26}$ have demonstrated that cardioplegic arrest and reperfusion impairs endothelium-mediated responses to substance $\mathrm{P}$ in nondiabetic patients, but this is the first study to demonstrate greater attenuation of vasorelaxation in diabetic patients. Importantly, ET receptor antagonism with BQ-123 improved vascular responses to ET-1 and substance P in both the diabetic and nondiabetic groups. These data suggest that increased sensitivity of the microvasculature to ET-1 occurs in both nondiabetic and diabetic patients undergoing $\mathrm{CABG}$ surgery. However, the diabetic vascular smooth muscle is more sensitive to the vasoconstrictor mechanisms of ET-1.
There are a few limitations to the atrial microvessel data presented in this study that should be borne in mind. First, no ET-1 dose-response curve was conducted. The responses of atrial microvessels to one concentration of ET-1 were studied, and hence it is not possible to determine the agonist sensitivity. Second, we did not assess the differences in internal diameter between diabetic and nondiabetic patients at increasing transmural pressures. Because the diabetic microvasculature might have greater myogenic tone, this assessment would have been useful. Furthermore, such a study would facilitate the correlation between wall tension and transmural pressure and would provide a sensitive index of alterations in myogenic tone. Finally, it is important to realize that in addition to ET-1, other factors, such as cyclooxygenase-derived products, might be important in the development of vascular dysfunction after CPB and reperfusion. Studies from Metais and colleagues ${ }^{26}$ have demonstrated that cardioplegic arrest and reperfusion causes enhanced serotonin-mediated vasoconstriction through the release of cyclooxygenase-2-derived products and impaired NO production. Although there might be an interaction between other vasoconstrictor products and ET-1, this was not assessed in the present study.

\section{Conclusions}

We determined the following: (1) the coronary effluent release of ET-1 was higher in diabetic than in nondiabetic patients after $\mathrm{CPB}$ and reperfusion; (2) diabetic coronary 
microvessels respond to $\mathrm{CPB}$ and reperfusion with greater ET-1-mediated vasoconstriction and diminished NO-mediated vasodilatation; and (3) these effects were attenuated by ET antagonism. ET-1 is an important mediator of ischemiareperfusion injury in diabetes. Furthermore, our results suggest that antagonism of ET receptors might represent a novel strategy for improving the resistance of the diabetic heart to ischemic injury during cardioplegic arrest and after reperfusion. Given the increasing evidence of a role of ET-1 as a mediator of perioperative injury, ${ }^{27-32}$ we suggest that a phase I study be conducted to develop ET receptor antagonists for high-risk patients undergoing cardiac operations.

\section{References}

1. Hammoud T, Tanguay JF, Bourassa MG. Management of coronary artery disease: therapeutic options in patients with diabetes. J Am Coll Cardiol. 2000;36:355-65.

2. Stamler J, Vaccaro O, Neaton JD, Wentworth D, for the Multiple Risk Factor Intervention Trial Research Group. Diabetes, other risk factors and 12-year cardiovascular mortality from men screened in the Multiple Risk Factor Intervention Trial. Diabetes Care. 1993;16:434-44.

3. Wingard DL, Barett-Connor E. Heart disease ad diabetes. In: National Diabetes Data Group. Diabetes in America. 2nd ed. Washington, DC: Government Printing Office; 1995. p. 429-48. NIH publication no. 95-1468.

4. Kannel W. Lipids, diabetes and coronary heart disease: insights from the Framingham Study. Am Heart J. 1985;110:1100-7.

5. Jacoby RM, Nesto RW. Acute myocardial infarction in the diabetic patient: pathophysiology, clinical course and prognosis. J Am Coll Cardiol. 1992;20:736-44.

6. Mak KH, Moliterno DJ, Granger CB, Miller DP, White HD, Wilcox $\mathrm{RG}$, et al. for the GUSTO-I investigators. Influence of diabetes mellitus on the clinical outcome in the thrombolytic era of acute myocardial infarction. J Am Coll Cardiol. 1997;30:171-9.

7. Woodfield SL, Lundergan CF, Reiner JS, Greenhouse SW, Thompson MA, Rohrbeck SC, et al. Angiographic findings and outcome in diabetic patients treated with thrombolytic therapy for acute myocardial infarction: the GUSTO-I experience. J Am Coll Cardiol. 1996; 28:1661-9.

8. Zuanetti G, Latini R, Maggioni AP, Santoro L, Franzosi MG. Influence of diabetes on mortality in acute myocardial infarction: data from GISSI-2 study. J Am Coll Cardiol. 1993;22:1788-94.

9. Morris JJ, Smith LR, Jones RH, Glower DD, Morris PB, Muhlbaier $\mathrm{LH}$, et al. Influence of diabetes and mammary artery grafting on survival after coronary bypass. Circulation. 1991;84(suppl 3):III27584.

10. Smith LR, Harell FE Jr, Rankin JS, Califf RM, Pryor DB, Muhlbaier $\mathrm{LH}$, et al. Determinants of early versus late cardiac death in patients undergoing coronary artery bypass graft surgery. Circulation. 1991; 84(suppl III):III245-53.

11. Alderman EL, Corley SD, Fisher LD, Chaitman BR, Faxon DP, Foster ED, et al. Five-year angiographic follow up of factors associated with progression of coronary artery disease in the Coronary Artery Surgery Study (CASS). The CASS Participating Investigators and Staff. J Am Coll Cardiol. 1993;22:1141-54.

12. Herlitz J, Wognsen GB, Emanuelsson H, Haglid M, Karlson BW, Karlsson T, et al. Mortality and morbidity in diabetic and non-diabetic patients during a 2-year period after coronary artery bypass grafting. Diabetes Care. 1996;19:698-703.
13. Barsness GW, Peterson ED, Ohman EM. Relationship between diabetes mellitus and long-term survival after coronary bypass and angioplasty. Circulation. 1997;96:2551-6.

14. Andersen B, Goldsmith GH, Spagnolo PJ. Neutrophil adhesive dysfunction in diabetes mellitus: the role of cellular and plasma factors. J Lab Clin Med. 1988;111:275-85.

15. McDonagh P, Hokoma JY. Microvascular perfusion and transport in the diabetic heart. Microcirculation. 2000;7:163-81.

16. Hearse DJ, Stewart DA, Chain EB. Diabetes and the survival and recovery of the anoxic myocardium. J Mol Cell Cardiol. 1975;7:397415 .

17. Kusama Y, Hearse DJ, Avkiran M. Diabetes and susceptibility to reperfusion induced ventricular arrhythmias. $\mathrm{J} \mathrm{Mol} \mathrm{Cell} \mathrm{Cardiol.}$ 1992;24:411-21

18. Rao V, Ivanov J, Weisel RD, Ikonomidis JS, Christakis GT, David TE. Predictors of low cardiac output syndrome after coronary artery bypass. J Thorac Cardiovasc Surg. 1996;112:38-51.

19. Fogelson BG, Nawas SI, Vigneswaran WT, Ferguson JL, Law WR, Sharma AC. Diabetic patients produce an increase in coronary sinus endothelin-1 after coronary artery bypass grafting. Diabetes. 1998;47: 1161-3.

20. Sharma AC, Fogelson BG, Nawas SI, Vigneswaran WT, Sam AD 2nd, Alden KJ, et al. Elevated coronary endothelin-1 but not nitric oxide in diabetics during CABG. Ann Thorac Surg. 1999;67:1659-63.

21. Yamauchi T, Ohnaka K, Takayanagi R, Umeda F, Nawata H. Enhanced secretion of endothelin-1 by elevated glucose levels from cultured bovine aortic endothelial cells. FEBS Lett. 1990;267:16-8.

22. Park JY, Takahara N, Gabriele A, Chou E, Naruse K, Suzuma K, et al. Induction of endothelin-1 expression by glucose: an effect of protein kinase C activation. Diabetes. 2000;49:1239-48.

23. Arikawa E, Verma S, Dumont AS, McNeill JH. Chronic bosentan treatment improves renal artery vascular function in diabetes. $J$ Hypertens. 2001;19:1-10.

24. Verma S, Arikawa E, McNeill JH. Long-term endothelin receptor blockade improves cardiovascular function in diabetes. Am J Hypertens. 2001;14:679-87.

25. Dorman BH, New RB, Bond BR, Mukerjee R, Mukhin YV, McElmurray $\mathrm{JH}$, et al. Myocyte endothelin exposure during cardioplegic arrest exacerbates contractile dysfunction after reperfusion. Anaesth Analg. 2000;90:1080-5.

26. Metais C, Li J, Simons M, Sellke FW. Serotonin induced coronary contraction increases after blood cardioplegia reperfusion. Role of COX-2 expression. Circulation. 1999;100(suppl II):328-34.

27. Bond BR, Dorman BH, Clair MJ, Walker CA, Pinosky ML, Reeves ST, et al. Endothelin-1 during and after cardiopulmonary bypass: association to graft sensitivity and postoperative recovery. $J$ Thorac Cardiovasc Surg. 2001;122:358-64.

28. Joffs C, Walker CA, Hendrick JW, Fary DJ, Almany DK, Davis JN, et al. Endothelin receptor subtype A blockade selectively reduces pulmonary pressure after cardiopulmonary bypass. J Thorac Cardiovasc Surg. 2001;122:365-70.

29. Mathieu P, Dupuis J, Carrier M, Cernacek P, Pellerin M, Perrault LP, et al. Pulmonary metabolism of endothelin-1 during on-pump and beating heart coronary artery bypass operations. J Thorac Cardiovasc Surg. 2001;121:1137-42.

30. Walker CA, Baicu SC, Goldberg AT, Widener CE, Fary DJ, Almany DK, et al. Temporal endothelin dynamics of the myocardial interstitium and systemic circulation in cardiopulmonary bypass. $J$ Thorac Cardiovasc Surg. 2000;120:864-71.

31. Dorman BH, Bond BR, Clair MJ, Walker CA, Pinosky ML, Reeves ST, et al. Temporal synthesis and release of endothelin within the systemic and myocardial circulation during and after cardiopulmonary bypass: relation to postoperative recovery. J Cardiothorac Vasc Anesth. 2000;14:540-5.

32. Ergul A, Joffs C, Walker AC, Spinale FG. Potential role of endothelin receptor antagonists in the setting of cardiopulmonary bypass: relevance to myocardial performance. Heart Failure Rev. 2001;6:287-94. 